NeuroRehabilitation 19 (2004) 335-341

\title{
Functional Neuroimaging in the Vegetative State
}

\section{Steven Laureys MD PhD}

Department of Neurology / Cyclotron Research Center,

University of Liège,

Sart Tilman B30,

4000 Liège, Belgium

e-mail: steven.laureys@ulg.ac.be

Tel : +3243662316

Fax : +3243662946

Keywords: positron emission tomography, functional magnetic resonance imaging, consciousness, vegetative state, minimally conscious state 


\begin{abstract}
The interest of functional imaging in patients in a vegetative state is twofold. First, the vegetative state continuous to represent a major clinical and ethical problem, in terms of diagnosis, prognosis, treatment, everyday management and end-of-life decisions. Second, it offers a lesional approach to the study of human consciousness and adds to the international research effort on identifying the neural correlate of consciousness. Cerebral metabolism has been shown to be massively reduced in the vegetative state. However, recovery of consciousness from vegetative state seems not always associated with substantial changes in global metabolism. Recent PET data indicate that some vegetative patients are unconscious not just because of a global loss of neuronal function, but due to an altered activity in a critical fronto-parietal cortical network and to abolished functional connections within this network and with non-specific thalamic nuclei. Recovery of consciousness was shown to be paralleled by a restoration of this cortico-thalamo-cortical interaction. Despite the metabolic impairment, external stimulation still induces neuronal activation as shown by both auditory and noxious stimuli. However, this activation is limited to primary cortices and dissociated from higherorder associative cortices, thought to be necessary for conscious perception.
\end{abstract}




\section{Introduction}

Technical progress of medicine has increased the number of patients who survive severe acute brain injury. Some of these patients recover from their coma within the first days after the insult, others will take more time and go through different stages before fully or partially recovering awareness (e.g., minimally conscious state) or will permanently lose all brain functions (i.e., brain death). Clinical practice shows how difficult it is to recognize unambiguous signs of conscious perception of the environment and of the self in these patients. This difficulty is reflected by frequent misdiagnoses of the vegetative state $[6,10]$. Objective assessment of residual brain function is difficult in patients with severe brain injury because their motor responses may be limited or inconsistent [28]. In addition, consciousness is not an all-or-none phenomenon but should rather be conceptualized as a continuum between different states. There is also a theoretical limitation to the certainty of our clinical diagnosis, since we can only infer the presence or absence of conscious experience in another person.

Functional neuroimaging will never replace our clinical assessment of patients in a vegetative state but it can objectively describe how deviant from normal is the cerebral activity and its regional distribution, at rest and under various conditions of stimulation.

\section{Brain metabolism in resting conditions}

Positron emission tomography (PET) studies have demonstrated that global brain metabolism in vegetative patients is reduced to 40 to $50 \%$ of normal values $[8,9,12,13,26,27,30,37$, 39, 40, 45, 47] (figure 1). Some studies however, have found normal cerebral metabolism[45] or blood flow[1] in patients in a vegetative state. Compared to cerebral glucose metabolism, cerebral blood flow seems to have a larger inter-patient variability in the vegetative state [30]. Brain metabolism is lower in persistent vegetative state than in acute vegetative state [47]. 
Progressive Wallerian and trans-synaptic degeneration could be responsible for this progressive loss of metabolic functioning over time. At present, there is no established correlation between brain metabolism depression and patient outcome.

\section{$<$ INSERT FIG 1 AROUND HERE}

A global depression of cerebral metabolism is not unique to vegetative state or coma. In slow wave sleep overall brain metabolism decreases to $60 \%$ of normal waking values [32]. Another example of transient metabolic depression is observed during general anesthesia. Indeed, when different anesthetics are titrated to the point of unresponsiveness, the resulting reduction in cerebral metabolism is comparable to that observed in vegetative patients [2-4] (figure 2).

In patients with a locked-in syndrome, overall supratentorial cerebral metabolism has been shown to be preserved partially [30] or fully [19], whereas cerebral metabolism in comatose patients is reduced to approximately $55 \%$ of normal values $[19,46]$.

\section{$<$ INSERT FIG 2 AROUND HERE}

Characteristic of patients in a vegetative state is the impairment of metabolism in the polymodal associative cortices (bilateral prefrontal regions, Broca's area, parieto-temporal and posterior parietal areas and precuneus) (figure 2) [26]. Interestingly, this fronto-parietal network is the most active in conscious waking $[5,16,32]$ and the least active in altered states of consciousness such as halothane- [4] or propofol- $[14,18]$ induced general anaesthesia, sleep [32, 34], hypnotic state [33, 38], and dementia [36, 42]; suggesting its critical role in human conscious cognition $[7,16,31]$. 
Another hallmark of the vegetative state is the relative sparing of metabolism in the brainstem (encompassing the pedunculopontine reticular formation, the hypothalamus and the basal forebrain) [22]. This allows for the maintenance of vegetative functions in these patients such as: sleep-wake cycles, autonomic and ventilatory control, and cranial nerve reflexes.

It is still controversial whether the cerebral metabolic dysfunction in vegetative patients reflects an irreversible structural neuronal loss [41] or functional and potentially reversible damage [24]. However, in the rare cases where vegetative patients recover consciuosness, PET shows a functional recovery of metabolism in these same cortical regions [27]. Moreover, the resumption of long-range functional connectivity between the frontoparietal cortices and between some of these and the intralaminar thalamic nuclei parallels the restoration of their functional integrity [23]. The cellular mechanisms which underlie this neuronal functional recovery remain speculative: axonal sprouting, neurite outgrowth, cell division (known to occur predominantly in associative cortices in normal primates) [15] could be proposed as candidate processes.

\section{$<$ INSERT FIG 3 AROUND HERE}

\section{Brain activation during stimulation}

Using the $\mathrm{H}_{2}{ }^{15} \mathrm{O}$ infusion technique, PET studies have measure changes in regional cerebral blood flow during auditory [11] and visual [35] stimulation. Menon and co-workers presented photographs of familiar faces and meaningless pictures in an upper boundary vegetative or lower boundary minimally conscious post-encephalitis patient (no evidence of responsiveness except occasional visual tracking of family members) who subsequently recovered. Intriguingly, the visual fusiform face area showed significant activation. Schiff and coworkers recently studied a series of chronic vegetative patients with unusual behavioral 
fragments (e.g., uttering single words in isolation of environmental stimulation [43]) by means of multimodal imaging techniques. Using PET, structural MRI and magnetoencephalography (MEG) they showed that isolated cerebral networks may remain active in well-documented but atypical cases of vegetative state [45].

Our group studied pain perception in persistent vegetative state patients [25]. High intensity noxious electrical stimulation activated midbrain, contralateral thalamus and primary somatosensory cortex in each and every one of the 15 vegetative patients studied, even in the absence of detectable cortical evoked potentials [25]. However, secondary somatosensory, insular, posterior parietal and anterior cingulate cortices, which were activated in all control subjects, failed to show activation in a single vegetative patient (figure 3). Moreover, in the vegetative patients, the activated primary somatosensory cortex was shown to exist as an island, functionally disconnected from higher-order associative cortices of the pain-matrix.

\section{$<$ INSERT FIG 4 AROUND HERE}

Likewise, although simple auditory click stimuli activated bilateral primary auditory cortices in vegetative patients, hierarchically higher-order multimodal association cortices could not be stimulated. Furthermore, a cascade of functional disconnections were observed along the auditory cortical pathways, from primary auditory areas to multimodal associative and limbic areas suggesting that the observed residual cortical processing in the vegetative state does not lead to integrative processes thought to be necessary for conscious awareness (figure 4) [21].

It is very important to stress that these results should be interpreted at the 'populationlevel' and must be used with great caution regarding clinical or ethical decisions in individual persons in a vegetative state. Future studies, using more powerful techniques such as 
functional MRI, are needed to assess noxious and cognitive processing of individual patients studied over time. 


\section{Differences between vegetative and minimally conscious patients}

Because criteria for the minimally conscious state have only recently been introduced, there are very few functional imaging studies of patients in this condition. Schiff and co-workers were the first to perform functional MRI in minimally conscious patients. They demonstrated a residual capacity to activate large integrative networks in two minimally conscious patients [17]. This preservation of large-scale networks may underlie rare instances of late recoveries of verbal fluency in such patients. Preliminary data from our laboratory show that overall cerebral metabolism is decreased to values comparable to those observed in the vegetative state and that quantification of resting cerebral metabolism does not permit to differentiate the vegetative state from the minimally conscious state in individuals patients [20]. However, using a simple auditory activation paradigm, we could show that each and every of our five minimally conscious patients showed a more widespread activation than did any of the 15 studied patients in a vegetative state (figure 4) [9]. In the former, activation encompassed not only primary but also auditory associative areas, suggesting a more elaborate level of processing. Moreover, cortico-cortical functional connectivity was significantly more efficient in minimally conscious as compared to vegetative patients, between auditory cortex and a large network of temporal and prefrontal associative cortices.

\section{$<$ INSERT FIG 5 AROUND HERE}

In line with that observation, we recently described that stimuli with emotional valence (cries and names) induced a much more widespread activation than did meaningless noise in the minimally conscious state [29]. Such context-dependent higher-order auditory processing shows that content does matter when talking to minimally conscious patients and 
encourage the use of neuromodulatory and cognitive rehabilitation strategies in this challenging patient population [44].

$<$ INSERT FIG 6 AROUND HERE

\section{Conclusion}

The vegetative state is a devastating medical condition of wakefulness unaccompanied by any evidence of awareness. At the patient's bedside, the evaluation of possible cognitive function is difficult because voluntary movements may be very limited, inconsistent and easily exhausted [28]. In our opinion, the use of PET on growing scale and the future use of functional MRI will substantially increase our understanding of severely brain-injured patients. However, in the absence of a generally accepted neural correlate of human consciousness [7], it remains very difficult to interpret functional neuroimaging data from severely brain-injured patients as a proof or disproof of their 'unconsciousness'. We hope that further research efforts will more closely correlate functional imaging with behavioral assessment, electrophysiological findings, and possibly outcome in patients in a vegetative or minimally conscious state.

\section{Acknowledgements}

SL is Research Associate supported by the Fonds National de la Recherche Scientifique de Belgique (FNRS) and by grants from the Fondation Médicale Reine Elisabeth, the Centre Hospitalier Universitaire Sart Tilman, the University of Liège, and the Mind Science Foundation. Marie-Elisabeth Faymonville, Pierre Maquet, André Luxen, Maurice Lamy and Gustave Moonen (Université de Liège) and Serge Goldman and Jacques Berré (Université 
Libre de Bruxelles) are acknowledged for their invaluable participation in the reviewed research projects. 


\section{References}

[1] C.D. Agardh, I. Rosen, E. Ryding, Persistent vegetative state with high cerebral blood flow following profound hypoglycemia., AnnNeurol 14 (1983), 482-486.

[2] M.T. Alkire, R.J. Haier, S.J. Barker, N.K. Shah, J.C. Wu, Y.J. Kao, Cerebral metabolism during propofol anesthesia in humans studied with positron emission tomography., Anesthesiology 82 (1995), 393-403.

[3] M.T. Alkire, R.J. Haier, N.K. Shah, C.T. Anderson, Positron emission tomography study of regional cerebral metabolism in humans during isoflurane anesthesia, Anesthesiology 86 (1997), 549-557.

[4] M.T. Alkire, C.J. Pomfrett, R.J. Haier, M.V. Gianzero, C.M. Chan, B.P. Jacobsen, J.H. Fallon, Functional brain imaging during anesthesia in humans: effects of halothane on global and regional cerebral glucose metabolism, Anesthesiology 90 (1999), 701-709.

[5] N.C. Andreasen, D.S. O'Leary, T. Cizadlo, S. Arndt, K. Rezai, G.L. Watkins, L.L. Ponto, R.D. Hichwa, Remembering the past: two facets of episodic memory explored with positron emission tomography., Am J Psychiatry 152 (1995), 1576-1585.

[6] K. Andrews, L. Murphy, R. Munday, C. Littlewood, Misdiagnosis of the vegetative state: retrospective study in a rehabilitation unit, BMJ 313 (1996), 13-16.

[7] B. Baars, T. Ramsoy, S. Laureys, Brain, conscious experience and the observing self, Trends in Neurosciences 26 (2003), 671-675.

[8] B. Beuthien-Baumann, W. Handrick, T. Schmidt, W. Burchert, L. Oehme, J. Kropp, G. Schackert, J. Pinkert, W.G. Franke, Persistent vegetative state: evaluation of brain metabolism and brain perfusion with PET and SPECT, Nucl Med Commun 24 (2003), 643-649.

[9] M. Boly, M.E. Faymonville, P. Peigneux, B. Lambermont, P. Damas, G. Del Fiore, C. Degueldre, G. Franck, A. Luxen, M. Lamy, G. Moonen, P. Maquet, S. Laureys, 
Auditory processing in severely brain injured patients: differences between the minimally conscious state and the persistent vegetative state, Arch Neurol 61 (2004), $233-238$.

[10] N.L. Childs, W.N. Mercer, H.W. Childs, Accuracy of diagnosis of persistent vegetative state., Neurology 43 (1993), 1465-1467.

[11] B. de Jong, A.T. Willemsen, A.M. Paans, Regional cerebral blood flow changes related to affective speech presentation in persistent vegetative state, Clin Neurol Neurosurg 99 (1997), 213-216.

[12] A.G. De Volder, A.M. Goffinet, A. Bol, C. Michel, B.T. de, C. Laterre, Brain glucose metabolism in postanoxic syndrome. Positron emission tomographic study., Arch Neurol 47 (1990), 197-204.

[13] E. Edgren, P. Enblad, A. Grenvik, A. Lilja, S. Valind, L. Wiklund, U. Hedstrand, H. Stjernstrom, L. Persson, U. Ponten, B. Langstrom, Cerebral blood flow and metabolism after cardiopulmonary resuscitation. A pathophysiologic and prognostic positron emission tomography pilot study, Resuscitation 57 (2003), 161-170.

[14] P. Fiset, T. Paus, T. Daloze, G. Plourde, P. Meuret, V. Bonhomme, N. Hajj-Ali, S.B. Backman, A.C. Evans, Brain mechanisms of propofol-induced loss of consciousness in humans: a positron emission tomographic study, J Neurosci 19 (1999), 5506-5513.

[15] E. Gould, A.J. Reeves, M.S. Graziano, C.G. Gross, Neurogenesis in the neocortex of adult primates, Science 286 (1999), 548-552.

[16] D.A. Gusnard, M.E. Raichle, Searching for a baseline: functional imaging and the resting human brain, Nat Rev Neurosci 2 (2001), 685-694.

[17] J. Hirsch, A. Kamal, D. Moreno, N. Petrovich, J. Giacino, F. Plum, N. Schiff, fMRI reveals intact cognitive systems for two minimally conscious patients, Society for Neuroscience, Abstracts 271 (2001), 1397. 
[18] K.K. Kaisti, J.W. Langsjo, S. Aalto, V. Oikonen, H. Sipila, M. Teras, S. Hinkka, L. Metsahonkala, H. Scheinin, Effects of sevoflurane, propofol, and adjunct nitrous oxide on regional cerebral blood flow, oxygen consumption, and blood volume in humans, Anesthesiology 99 (2003), 603-613.

[19] S. Laureys, J. Berré, S. Goldman, Cerebral function in coma, vegetative state, minimally conscious state, locked-in syndrome and brain death, in: 2001 Yearbook of Intensive Care and Emergency Medicine, J L Vincent, ed, Springer-Verlag, Berlin, 2001, pp. 386-396.

[20] S. Laureys, M. Faymonville, M. Ferring, C. Schnakers, S. Elincx, N. Ligot, S. Majerus, S. Antoine, N. Mavroudakis, J. Berre, A. Luxen, J.L. Vincent, G. Moonen, M. Lamy, S. Goldman, P. Maquet, Differences in brain metabolism between patients in coma, vegetative state, minimally conscious state and locked-in syndrome, 7th Congress of the European Federation of Neurological Societies (FENS), 30 August-2 September, 2003, Helsinki, Finland, European Journal of Neurology 10 (2003) 224, Suppl 1 (2003),

[21] S. Laureys, M.E. Faymonville, C. Degueldre, G.D. Fiore, P. Damas, B. Lambermont, N. Janssens, J. Aerts, G. Franck, A. Luxen, G. Moonen, M. Lamy, P. Maquet, Auditory processing in the vegetative state, Brain 123 (2000), 1589-1601.

[22] S. Laureys, M.E. Faymonville, S. Goldman, C. Degueldre, C. Phillips, B. Lambermont, J. Aerts, M. Lamy, A. Luxen, G. Franck, P. Maquet, Impaired cerebral connectivity in vegetative state, in: Physiological Imaging of the Brain with PET, A Gjedde, S B Hansen, G M Knudsen, O B Paulson, ed, Academic Press, San Diego, 2000, pp. 329334. 
[23] S. Laureys, M.E. Faymonville, A. Luxen, M. Lamy, G. Franck, P. Maquet, Restoration of thalamocortical connectivity after recovery from persistent vegetative state, Lancet 355 (2000), 1790-1791.

[24] S. Laureys, M.E. Faymonville, G. Moonen, A. Luxen, P. Maquet, PET scanning and neuronal loss in acute vegetative state, Lancet 355 (2000), 1825-1826.

[25] S. Laureys, M.E. Faymonville, P. Peigneux, P. Damas, B. Lambermont, G. Del Fiore, C. Degueldre, J. Aerts, A. Luxen, G. Franck, M. Lamy, G. Moonen, P. Maquet, Cortical processing of noxious somatosensory stimuli in the persistent vegetative state, Neuroimage 17 (2002), 732-741.

[26] S. Laureys, S. Goldman, C. Phillips, P. Van Bogaert, J. Aerts, A. Luxen, G. Franck, P. Maquet, Impaired effective cortical connectivity in vegetative state: preliminary investigation using PET, Neuroimage 9 (1999), 377-382.

[27] S. Laureys, C. Lemaire, P. Maquet, C. Phillips, G. Franck, Cerebral metabolism during vegetative state and after recovery to consciousness, J Neurol Neurosurg Psychiatry 67 (1999), 121

[28] S. Laureys, S. Majerus, G. Moonen, Assessing consciousness in critically ill patients, in: 2002 Yearbook of Intensive Care and Emergency Medicine, J L Vincent, ed, SpringerVerlag, Heidelberg, 2002, pp. 715-727.

[29] S. Laureys, F. Perrin, M.E. Faymonville, C. Schnakers, M. Boly, V. Bartsch, S. Majerus, G. Moonen, P. Maquet, Cerebral processing in the minimally conscious state, Neurology 63 (2004), 916-619.

[30] D.E. Levy, J.J. Sidtis, D.A. Rottenberg, J.O. Jarden, S.C. Strother, V. Dhawan, J.Z. Ginos, M.J. Tramo, A.C. Evans, F. Plum, Differences in cerebral blood flow and glucose utilization in vegetative versus locked-in patients, AnnNeurol 22 (1987), 673682. 
[31] H.C. Lou, B. Luber, M. Crupain, J.P. Keenan, M. Nowak, T.W. Kjaer, H.A. Sackeim, S.H. Lisanby, Parietal cortex and representation of the mental Self, Proc Natl Acad Sci US A (2004),

[32] P. Maquet, C. Degueldre, G. Delfiore, J. Aerts, J.M. Peters, A. Luxen, G. Franck, Functional neuroanatomy of human slow wave sleep., J Neurosci 17 (1997), 28072812.

[33] P. Maquet, M.E. Faymonville, C. Degueldre, G. Delfiore, G. Franck, A. Luxen, M. Lamy, Functional neuroanatomy of hypnotic state, Biol Psychiatry 45 (1999), 327333.

[34] P. Maquet, J. Peters, J. Aerts, G. Delfiore, C. Degueldre, A. Luxen, G. Franck, Functional neuroanatomy of human rapid-eye-movement sleep and dreaming., Nature 383 (1996), 163-166.

[35] D.K. Menon, A.M. Owen, E.J. Williams, P.S. Minhas, C.M. Allen, S.J. Boniface, J.D. Pickard, Cortical processing in persistent vegetative state., Lancet 352 (1998), 200.

[36] S. Minoshima, B. Giordani, S. Berent, K.A. Frey, N.L. Foster, D.E. Kuhl, Metabolic reduction in the posterior cingulate cortex in very early Alzheimer's disease, AnnNeurol 42 (1997), 85-94.

[37] T. Momose, T. Matsui, N. Kosaka, Effect of cervical spinal cord stimulation (cSCS) on cerebral glucose metabolism and blood flow in a vegetative patient assessed by positron emission tomography (PET) and single photon emission computed tomography (SPECT). Radiat Med 7 (1989), 243-246.

[38] P. Rainville, R.K. Hofbauer, T. Paus, G.H. Duncan, M.C. Bushnell, D.D. Price, Cerebral mechanisms of hypnotic induction and suggestion, J Cogn Neurosci 11 (1999), 110125. 
[39] J. Rudolf, M. Ghaemi, W.F. Haupt, B. Szelies, W.D. Heiss, Cerebral glucose metabolism in acute and persistent vegetative state, JNeurosurgAnesthesiol 11 (1999), 17-24.

[40] J. Rudolf, J. Sobesky, M. Ghaemi, W.D. Heiss, The correlation between cerebral glucose metabolism and benzodiazepine receptor density in the acute vegetative state, Eur $J$ Neurol 9 (2002), 671-677.

[41] J. Rudolf, J. Sobesky, M. Grond, W.D. Heiss, Identification by positron emission tomography of neuronal loss in acute vegetative state., Lancet 355 (2000), 155.

[42] E. Salmon, F. Collette, C. Degueldre, C. Lemaire, G. Franck, Voxel-based analysis of confounding effects of age and dementia severity on cerebral metabolism in Alzheimer's disease [In Process Citation], Hum Brain Mapp 10 (2000), 39-48.

[43] N. Schiff, U. Ribary, F. Plum, R. Llinás, Words without mind, J Cogn Neursci 11 (1999), 650-656.

[44] N.D. Schiff, F. Plum, A.R. Rezai, Developing prosthetics to treat cognitive disabilities resulting from acquired brain injuries, Neurol Res 24 (2002), 116-124.

[45] N.D. Schiff, U. Ribary, D.R. Moreno, B. Beattie, E. Kronberg, R. Blasberg, J. Giacino, C. McCagg, J.J. Fins, R. Llinas, F. Plum, Residual cerebral activity and behavioural fragments can remain in the persistently vegetative brain, Brain 125 (2002), 12101234

[46] C. Tommasino, Brain glucose metabolism in the comatose state and in post-comatose syndromes., Minerva Anestesiol 60 (1994), 523-525.

[47] C. Tommasino, C. Grana, G. Lucignani, G. Torri, F. Fazio, Regional cerebral metabolism of glucose in comatose and vegetative state patients., JNeurosurgAnesthesiol 7 (1995), 109-116. 


\section{Figure legends}

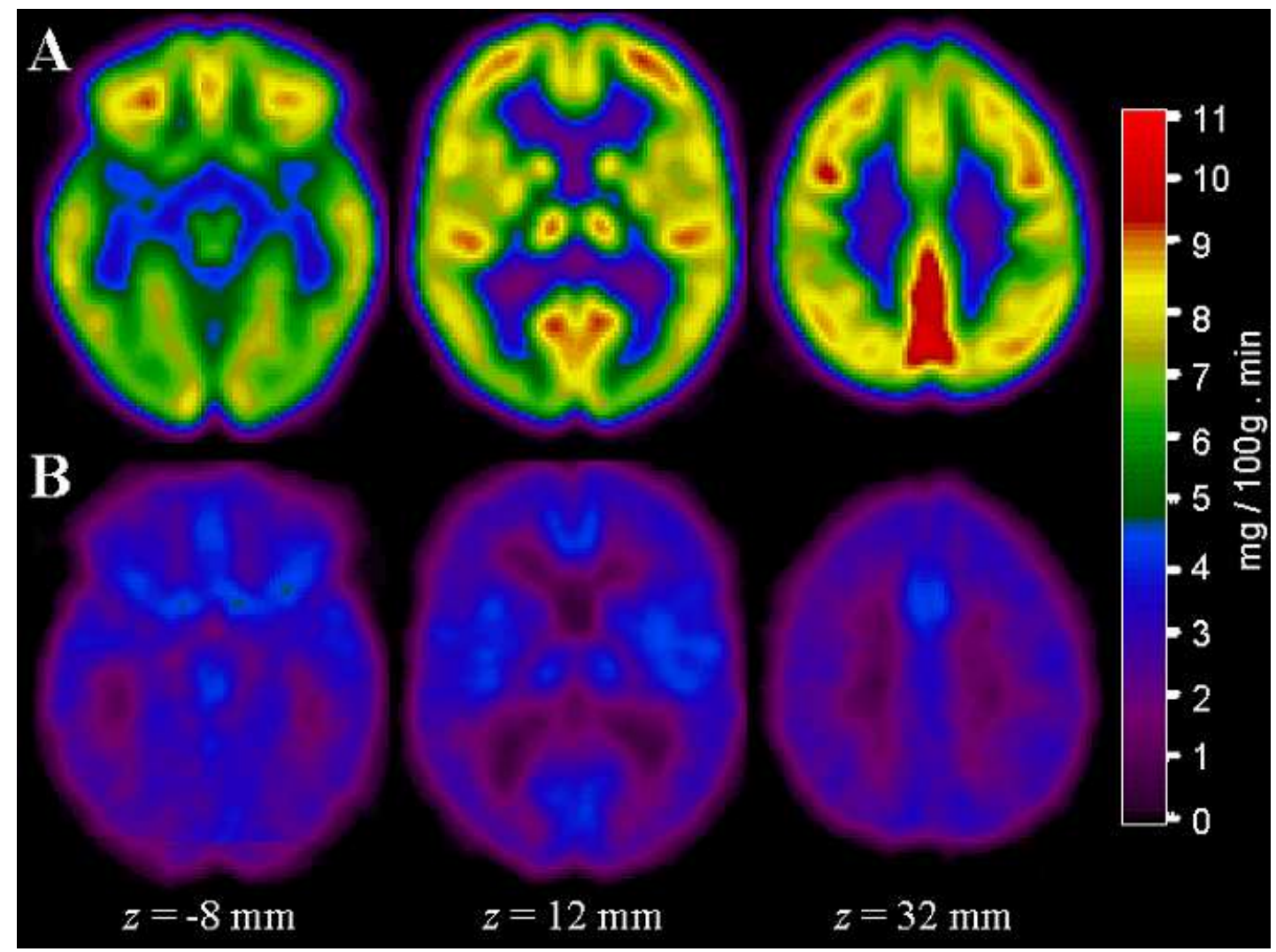

Fig 1. (A) Averaged image of glucose metabolism obtained in 110 control subjects (mean age 42; range 18 to 76 years) and (B) in 33 patients in a vegetative state (mean age 42; range 13 to 82 years), spatially normalised into standardised stereotaxic space and shown in transverse sections relative to the anterior-posterior commisural line. Glucose metabolic rates (expressed in $\mathrm{mg} / 100 \mathrm{~g} \cdot \mathrm{min}$ ) are proportional to the artificial colourscale. To allow a better comparison of global patterns, controls and patients are represented according to the same scale. Note the marked depression of metabolic rates in vegetative state patients of about $40 \%$ of normal values. 


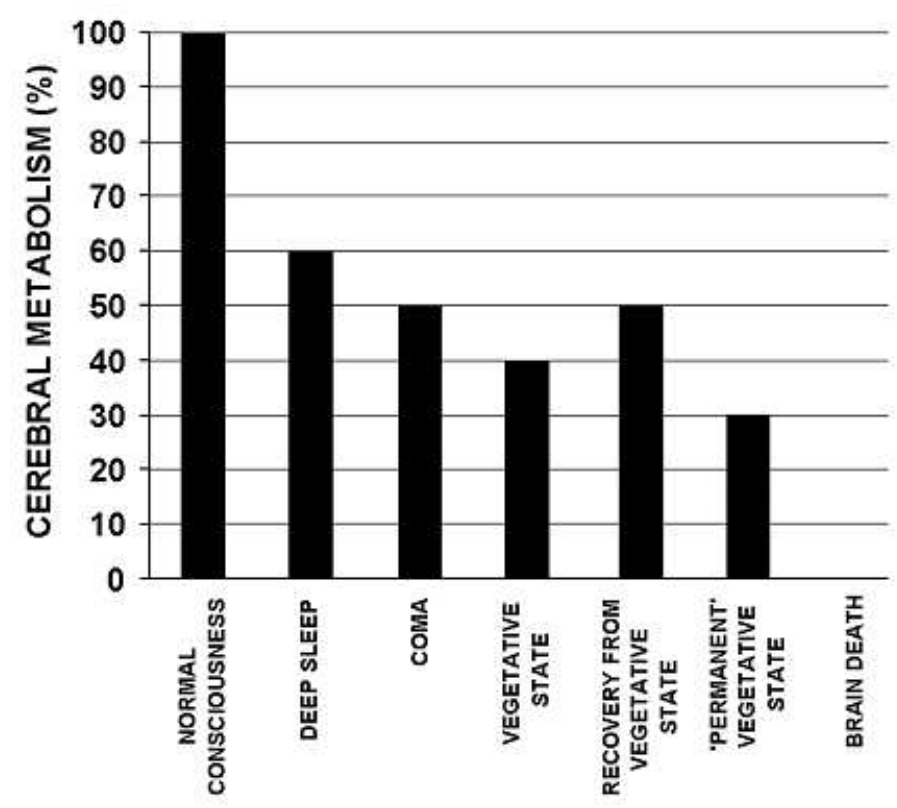

Fig 2. Mean global cerebral metabolism in different states of altered consciousness (for references see text). 


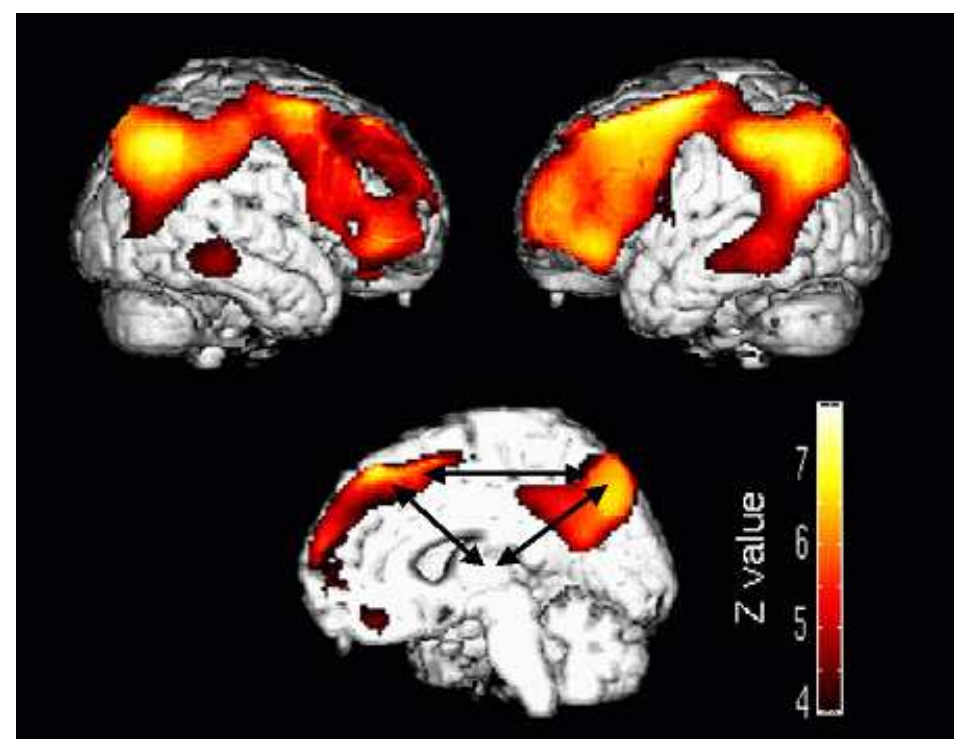

Fig 3. The common functional neuroanatomy of vegetative state. Using Statistical Parametric Mapping (www.fil.ion.ucl.ac.uk/spm) we identified areas where metabolism was relatively most impaired in vegetative patients compared to controls. Results are shown on a surface rendered 3-D magnetic resonance image at voxel level corrected $\mathrm{p}<0.05$. Note that the most dysfunctional regions are the associative cortices (medial and lateral prefrontal and premotor encompassing frontal eye field- areas and medial and lateral parietal and temporal areas) The arrows represent the impaired cortico-cortical and cortico-thalamo-cortical connections. 

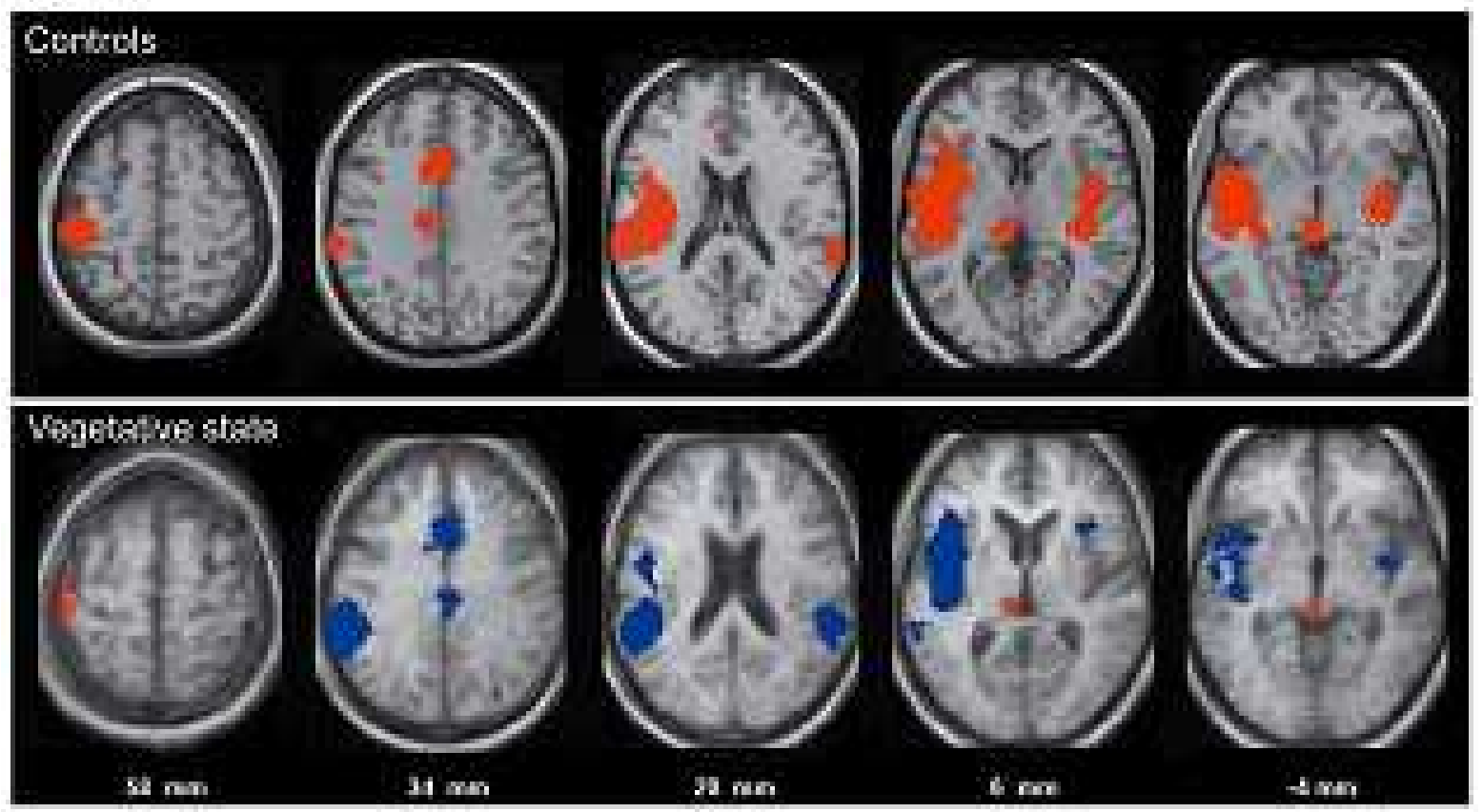

Fig 4. (upper part) Brain regions, shown in red, that activated during noxious stimulation in controls (lower part) Brain regions that activated during stimulation in patients in a persistent vegetative state, shown in red and regions that failed to activate shown in blue. Projected on transverse sections of a normalized brain MRI template in controls and on the mean MRI of the patients (distances are relative to the bicommisural plane). (Reprinted from [25]). 


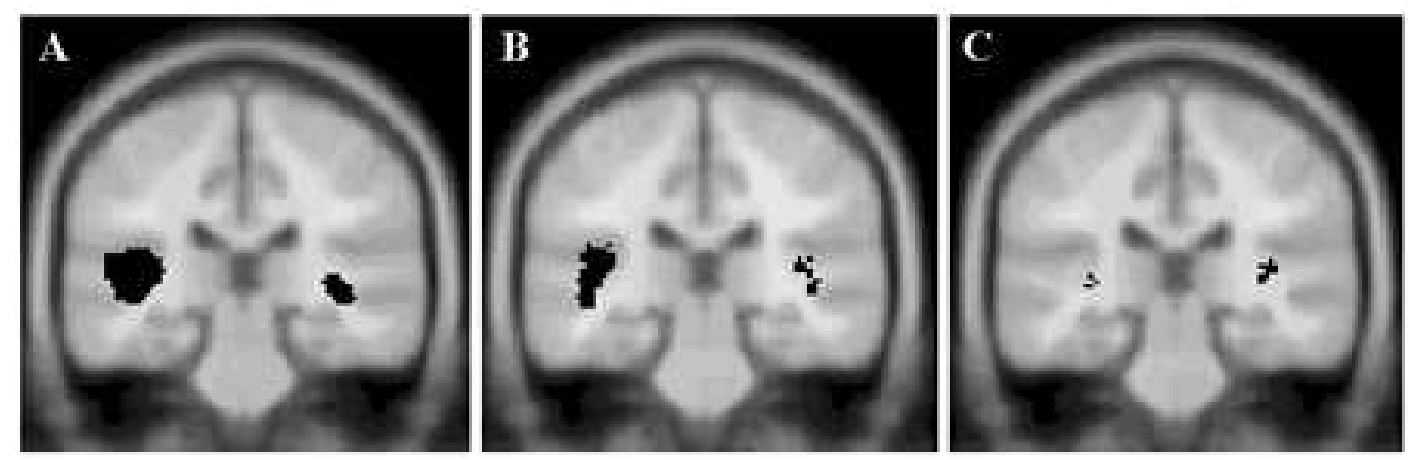

Fig 5. Brain regions showing activation during auditory stimulation in (A) controls, (B) MCS and (C) PVS patients. Reprinted from [9]. 

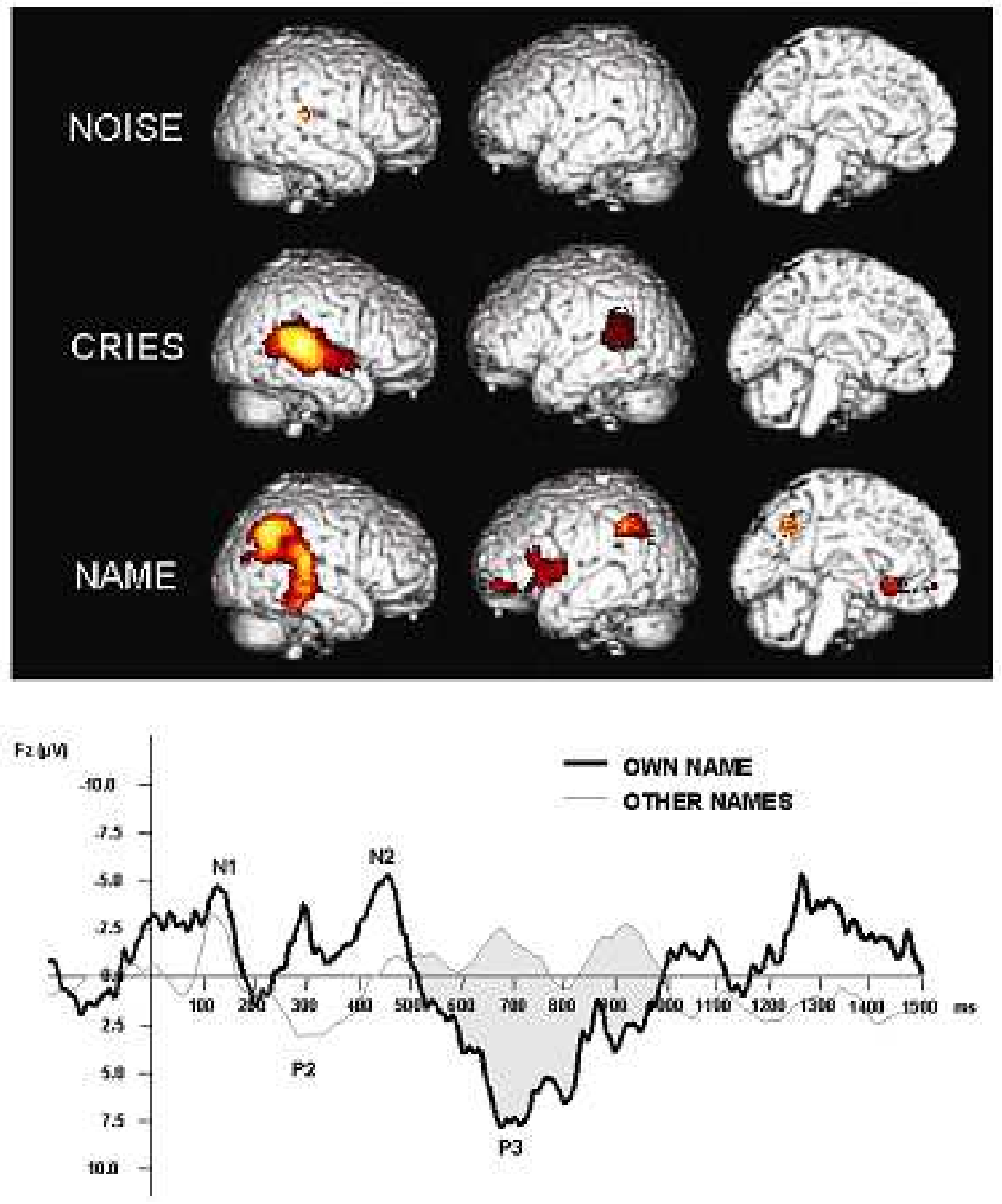

Fig 6. Emotional processing in the minimally conscious state. Upper panel: Brain areas that showed activation (compared to rest) during presentation of noise, cries and the patient's own name projected on a 3D-MRI. Lower panel: Event related potentials in response to the patient's own name (thick line) and to other names (thin line). Data are averages from 3 sessions (each containing 2x27 stimuli) obtained during PET scanning. Reprinted from [29]. 